\title{
Electrospun Silicon Oxycarbide Ultrafine Fibers Derived from Polycarbosilane
}

\author{
WU Nan ${ }^{1,2}$, WAN Lynn Yuqin ${ }^{2}$, WANG Ying-De ${ }^{1}$, FRANK KO ${ }^{2}$ \\ (1. Science and Technology on Advanced Ceramic Fibers and Composites Laboratory, National University of Defense Tech- \\ nology, Changsha 410073, China; 2. Department of Materials Engineering, the University of British Columbia, Vancouver, \\ Canada, V6T 1Z4)
}

\begin{abstract}
Silicon oxycarbide (SiOC) ultrafine fibers with uniform distribution were prepared via electrospinning of polycarbosilane (PCS)/polystyrene followed by oxidation and pyrolysis at $1100^{\circ} \mathrm{C}$. The diameter of SiOC fibers ranged from 500 to $900 \mathrm{~nm}$ through adjusting PCS concentration. The average tensile strength of SiOC fiber mat was 8.88 MPa. The obtained SiOC fibers also displayed outstanding thermal stability and chemical resistance, making them promising materials as smart filters and catalyst supports in harsh environment.
\end{abstract}

Key words: electrospinning; polycarbosilane; silicon oxycarbide; ceramic fibers

Owing to the excellent high-temperature resistance and mechanical properties, silicon-based ceramic fibers have been widely applied in aerospace and nuclear energy fields ${ }^{[1]}$. Particularly, ultrafine SiC or SiOC fibers have received much more attention due to their high surface-to-volume ratio, which demonstrated potential applications as catalyst supports ${ }^{[2]}$, filtration device ${ }^{[3]}$, and composite membrane ${ }^{[4]}$.

Among various chemical and physical synthesis methods, electrospinning is considered as a simple and versatile method for production of continuous ceramic micro/nanofibers in large scale ${ }^{[5]}$. Recently, we have successfully fabricated hierarchically porous $\mathrm{SiC}$ microfibers ${ }^{[6]}$ and $\mathrm{ZrO}_{2} / \mathrm{SiC}$ gradient fibers ${ }^{[7]}$ using electrospinning combined with polymer derived ceramic (PDC) techniques. PDC route is a prominent method for the fabrication of silicon-based ceramic materials, especially for the fiber and layer forms, which is a challenge to the traditional powder technology ${ }^{[8]}$.

Polycarbosilane (PCS) known as the most common precursor polymer for the synthesis of silicon-based ceramic fibers since invented by Yajima ${ }^{[9]}$. However, the fabrication of SiOC ultrafine fibers with uniform distribution diameter below $1 \mu \mathrm{m}$ through electrospinning of PCS is rarely reported due to the low molecular weight of PCS with large amounts of branched chains, which requires a high mass ratio of about $60 \%$ in aprotic solvent for electrospinning. Though the $\mathrm{Si}(\mathrm{O}) \mathrm{C}$ nanofibers have been fabricated by core-shell electrospinning ${ }^{[10-11]}$, the complicated process and inhomogeneous fiber morphology greatly limited their large-scale production and application.

Herein, we prepared beads-free SiOC fibers by electrospinning of PCS droplets entrapped with the polystyrene (PS) solution followed by oxidation and high-temperature pyrolysis. The diameter of the obtained fibers ranges from 500 $\mathrm{nm}$ to $900 \mathrm{~nm}$ through adjusting PCS concentration in the solution. The thermal stability, erosion resistance and mechanical strength of fiber mat were also investigated in this work.

\section{Experimental}

\subsection{Fabrication of SiOC ultrafine fibers}

Polystyrene (PS, $M_{n}=1,928,000$, Scientific polymer production INC), polycarbosilane (PCS, prepared in CFC, National University of Defense Technology), Sodium dodecyl sulfate (SDS, MP Biomedicals), xylene (Fisher scientific) and dimethylformamide (DMF, Anachemia) were used without purification.

In a typical process, $3 \mathrm{wt} \%$ PS was dissolved into the mixed solvent of xylene and DMF. Then, PCS and SDS were added to the PS solution and stirred at room temperature for $12 \mathrm{~h}$ until a transparent solution was obtained. Electrospinning was conducted by a Drum Electrospinning Unit (Kato Tech Inc., Japan). The precursor solution was transferred into a $10 \mathrm{ml}$ syringe with a constant flow rate of $0.8 \mathrm{~mL} / \mathrm{h}$. A high voltage of $11-13 \mathrm{kV}$ was applied between the metal needle and the grounded drum. The relative humidity was controlled at $25 \%-30 \%$. After electrospinning, the as-spun fiber membrane was stabilized at $210^{\circ} \mathrm{C}$ for $2 \mathrm{~h}$ at a ramp rate of $1^{\circ} \mathrm{C} / \mathrm{min}$.

Received date: 2017-04-05; Modified date: 2017-07-05

Foundation item: National Natural Science Foundation of China (51173202)

Biography: WU Nan (1989-), male, candidate of PhD. E-mail: lierenwn@163.com

Corresponding author: WANG Ying-De, professor. E-mail: wyd502@163.com; FRANK KO, professor. E-mail: frank.ko@ubc.ca 
Calcination was done at $1100^{\circ} \mathrm{C}$ for $2 \mathrm{~h}$ under Ar atmosphere. The final SiOC- $x$ is named after the weight concentration of PCS. The concentration of PCS in the spinning solution of SiOC-9, SiOC-15 and SiOC-21 are $9 w t \%, 15 w t \%$ and $21 w t \%$, respectively.

\subsection{Characterization}

The morphology of fibers was studied by scanning electron microscopy (SEM, Hitachi S-3000, Japan). The average diameter of the ultrafine fibers was obtained through analyzing about 150 fibers by ImageJ software. $\mathrm{X}$-ray diffraction (XRD) patterns were collected in the range of $10^{\circ}-80^{\circ}$ using Rigaku multiflex diffractometer. $\mathrm{X}$-ray photoelectron spectroscopy (XPS) was carried out on a Thermo Scientific Escalab 250Xi machine. Thermal gravimetric analysis (TGA) was operated on TGA Q500 instrument in air at a ramping rate of $10{ }^{\circ} \mathrm{C} / \mathrm{min}$. The tensile strength of the fiber mats were tested on a Kawabata KES-G1 microtensile tester as described in the previous paper $^{[12]}$. The results of the experiment were expressed in load (gram force) vs. displacement. The specific stress in g/Tex was then calculated using the following equation:

$$
\sigma_{\text {specific }}(\mathrm{g} / \mathrm{Tex})=\frac{\operatorname{load}(\mathrm{g})}{\text { Areal Density }\left(\mathrm{g} / \mathrm{m}^{2}\right) \times \text { Width }(\mathrm{mm})}
$$

Then the specific stress in $g /$ Tex was converted to engineering stress by the equation below:

$$
\sigma_{\text {Eng }}(\mathrm{MPa})=\sigma_{\text {specific }}(\mathrm{g} / \mathrm{Tex}) \times 9.81 \times \rho_{\text {mat }}
$$

The strain was calculated by dividing the displacement by the gauge length.

\section{Results and discussion}

In this study, high-molecular weight PS was introduced into the spinning solution to decrease the required PCS concentration for electrospinning and facilitate the electrospinning process. Previous study showed that low molecular weight polymer with dilute concentration can be electrospun in emulsion phase ${ }^{[13]}$. Surfactant is of vital important for emulsion electrospinning, which can decrease the surface tension and improve the dispersion uniformity of the micelles in the matrix solution ${ }^{[14]}$. SDS was chosen as the surfactant to facilitate the electrospinning process in this work. Figure 1(a) shows beaded fibers were obtained from the solution without SDS. The presence of beads in the fibers usually weakens the mechanical properties of fiber mats. Addition of $1 \mathrm{wt} \%$ SDS eliminated the formation of beads, as shown in Fig. 1(b). This implied that the addition of SDS lowered the surface tension and enhanced the rheological property, further improved the uniformity of the resultant fibers. As can be seen from Fig. 1(b), the as-spun fibers had a wrinkled skin which was a consequence of the rapid evaporation of solvent in the low humidity environment (30\% relative humidity) ${ }^{[15]}$. The diameter of as-spun SiOC-15 fibers was measured to be $(900 \pm 300) \mathrm{nm}$. The fiber diameter decreased slightly to $(820 \pm 320) \mathrm{nm}$ after stabilization process while the surface became smoother due to the shrinkage (Fig. 1(c)). After pyrolyzed at $1100^{\circ} \mathrm{C}$ in argon, the diameter of SiOC-15 further decreased to $(630 \pm 125) \mathrm{nm}$ and the fiber mat shrinked about $24.4 \%$ compared to pre-oxidized mat (the fiber mat area changed from 21.1 to $16 \mathrm{~cm}^{2}$, Fig. 1(d)).

The viscosity of solution plays an important role in determining the diameter of obtained fibers. High viscosity increases the relaxation time and hinders the elongation of the ejected jets, resulting in larger fiber diameter ${ }^{[16]}$. Here, the effects of the concentration of PCS in the solution on SiOC fiber diameter we investigated. SEM images revealed the corresponding morphology of the fibers as shown in Fig. 2. All the three fibers are free of beads and uniform with wrinkled surface after pyrolysis. The wrinkled surface of SiOC fibers suggests that the fibers have potential applications as catalyst carriers with increased number of active anchors for catalysts. The diameter distribution for SiOC-9, SiOC-15 and SiOC-21 was summarized in the insets of Fig. 2. As expected, the average diameter of SiOC fiber decreased from $875 \mathrm{~nm}$ to $505 \mathrm{~nm}$ as the PCS concentration decreased from $21 w t \%$ to $9 w t \%$. The elemental composition of different SiOC fibers was analyzed by EDS. Ignoring the small contents of sodium, sulfur and gold, the atomic proportion of SiOC-9 was found to be about $16.3 \% \mathrm{Si}, 30.1 \% \mathrm{O}$ and $53.6 \% \mathrm{C}$. The SiOC ceramics with high carbon content possessed better mechanical properties with improved creep and oxidation resistance ${ }^{[17]}$.
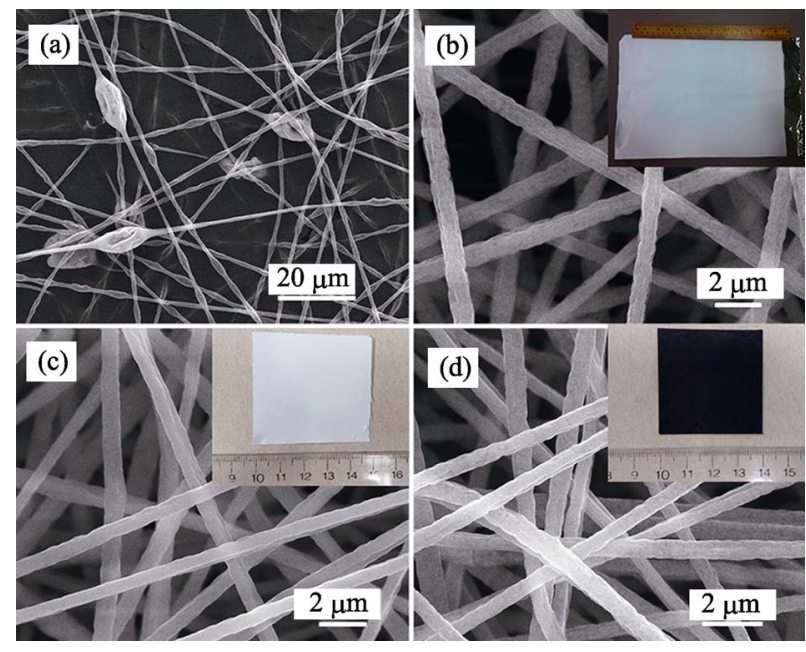

Fig. 1 SEM images of (a) as-spun PS/PCS fibers without SDS, (b) as-spun PS/PCS fibers with SDS, (c) pre-oxidized PS/PCS fibers, and (d) SiOC-15 fibers after pyrolysis Insets are the corresponding digital pictures 

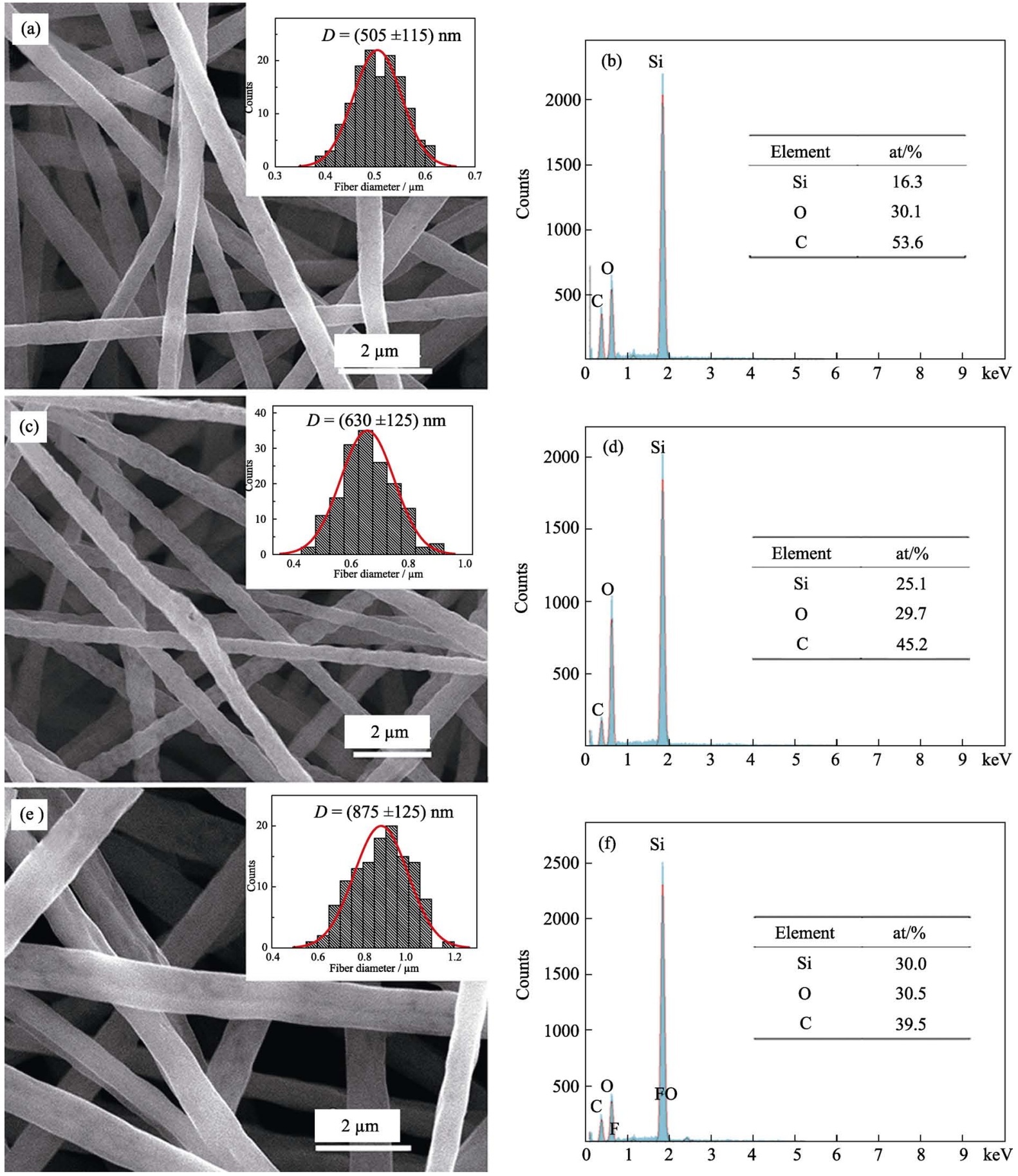

Fig. 2 SEM images, diameter distribution and corresponding EDS spectra of (a, b) SiOC-9, (c, d) SiOC-15 and (e, f) SiOC-21

The chemical status of the existed elements was analyzed by XPS, as shown in Fig. 3. XPS survey scan indicates the presence of sodium, oxygen, carbon and silicon (Fig. 3(a)). The small content of sodium (2.5\%) came from the addition of SDS. In the C1s spectrum of SiOC-15, a noticeable characteristic peak for $\mathrm{C}-\mathrm{C}$ bond at $284.6 \mathrm{eV}$ was observed, suggesting the existence of free carbon in the carbonized fibers. A peak at around $284.0 \mathrm{eV}$ characterizing $\mathrm{SiO}_{x} \mathrm{C}_{y}$ was also detected. The $\mathrm{Si} 2 \mathrm{p}$ spectrum in Fig. 3(c) proved the existence of $\mathrm{SiO}_{2}$ (103.5 eV), $\mathrm{SiO}_{3} \mathrm{C}(102.9 \mathrm{eV}), \mathrm{SiO}_{2} \mathrm{C}_{2}(102.4 \mathrm{eV})$ and
$\mathrm{SiOC}_{3}(101.6 \mathrm{eV})$ on the surface of fibers ${ }^{[18]}$. As shown in Fig. 3(d), the peak for $\mathrm{SiO}_{x} \mathrm{C}_{y}$ at $532.4 \mathrm{eV}$ was also found in the O1s spectrum. All the above results demonstrated that the obtained SiOC fiber surface was mainly composed of free carbon and $\mathrm{SiO}_{x} \mathrm{C}_{y}$ phase.

Typical stress-strain tensile properties of the SiOC fiber mats are shown in Fig. 4. The average tensile strength for SiOC-9, SiOC-15 and SiOC-21 is $0.45 \mathrm{MPa}$, 2.24 $\mathrm{MPa}$ and 8.88 $\mathrm{MPa}$, respectively. Wan et al. have showed that low fiber packing density (high porosity) of nonwoven mats will decrease the mechanical strength of 

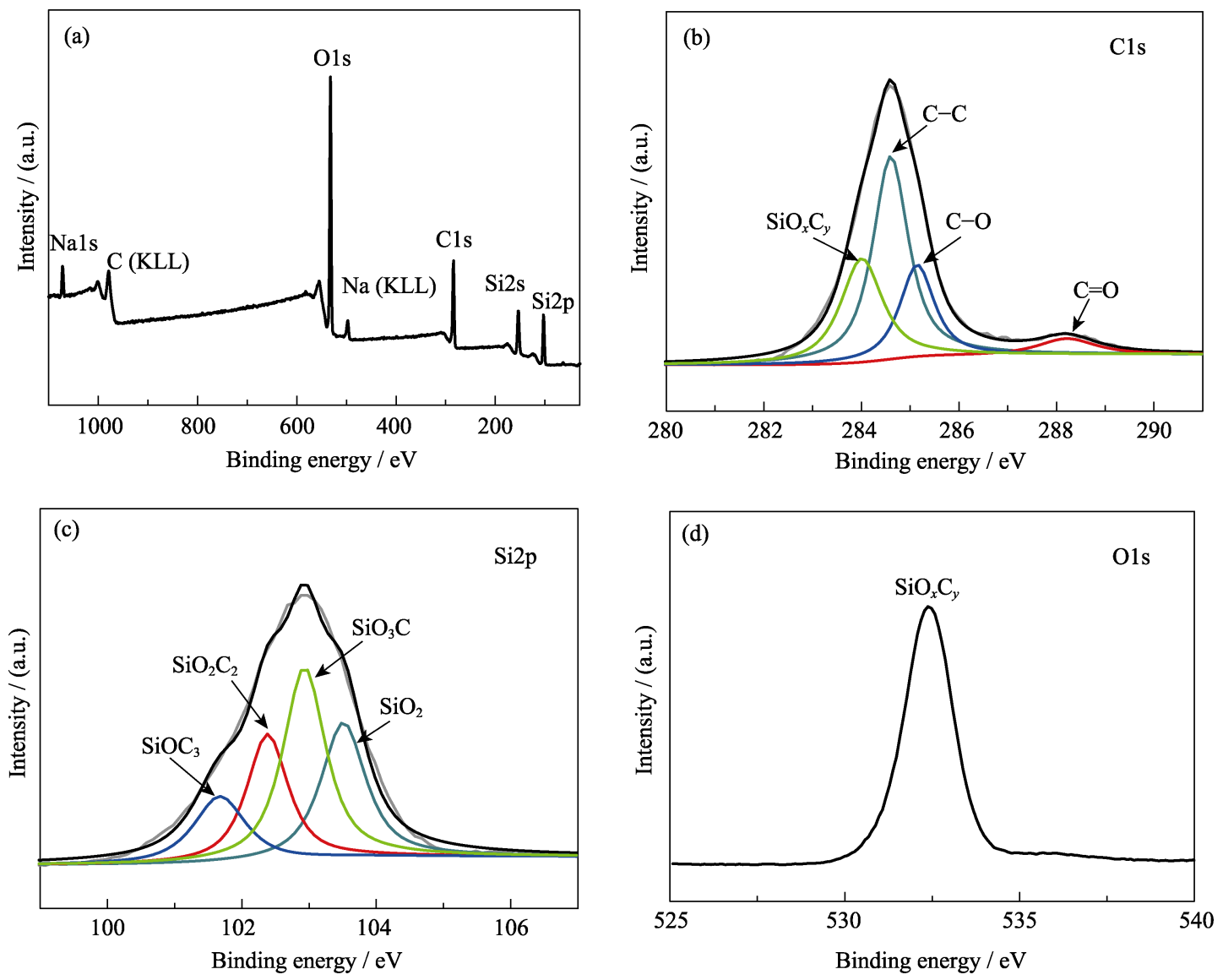

Fig. 3 (a) XPS survey, (b) C1s, (c) Si2p and (d) O1s spectra of SiOC-15

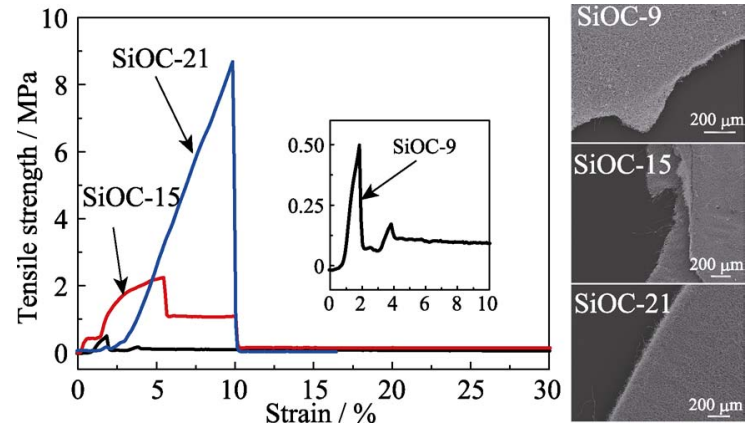

Fig. 4 Tensile strength of SiOC-9, SiOC-15 and SiOC-21. The right of pictures are the corresponding SEM images of breaking section

the mats ${ }^{[19]}$. The low porosity and high bulk density contribute mostly to the relatively higher tensile strength of SiOC-21. SiOC-15 demonstrated a platform-ladder like broken model which was different from SiOC-9 and SiOC-21. This was attributed to the existence of laminar fracture in the mat, as confirmed by SEM (on the right of Fig. 4). Besides, a pseudo-yield point was observed in SiOC-15 curve, caused by the fiber slippage ${ }^{[12]}$.

Thermal stability and erosion resistance are important for the future practical applications of SiOC fibers in harsh environment. The thermal stability of samples was investigated with TGA by treating the samples at high-temperature in air. Figure 5(a) shows the TGA curve of SiOC-15. The residual weight slightly increased when the treatment temperature went above $500^{\circ} \mathrm{C}$ as $\mathrm{SiOC}$ phase was converted into $\mathrm{SiO}_{2}$. The morphology of SiOC-15 fibers displayed no change after $1 \mathrm{~h}$ treating in air at $500^{\circ} \mathrm{C}$ (inset of Fig. 5(a)), suggesting an excellent thermal stability of the SiOC ultrafine fibers at high temperature. The erosion experiment showed that the SiOC fibers maintained their integral features after treated in hot $\mathrm{H}_{2} \mathrm{SO}_{4}$ and $\mathrm{KOH}$ solution (Fig. 5(b) and (c)). XRD patterns in Fig. 5(d) confirmed that there is no phase transformation after the harsh treatments. The good thermal stability and erosion resistance indicated potential applications of the SiOC ultrafine fibers as catalyst supports and filters in harsh environment.

\section{Conclusions}

In conclusion, SiOC fibers with average diameter of $500 \mathrm{~nm}$ to $875 \mathrm{~nm}$ were successfully prepared by electrospinning of different concentration PCS/PS solution, followed by pre-oxidation and pyrolysis. The SiOC fibers display enhanced thermal stability at $500^{\circ} \mathrm{C}$ in air and excellent chemical resistance. These outstanding properties of obtained SiOC fiber mats make them promising candidates for filters and catalyst supports in harsh environment. 

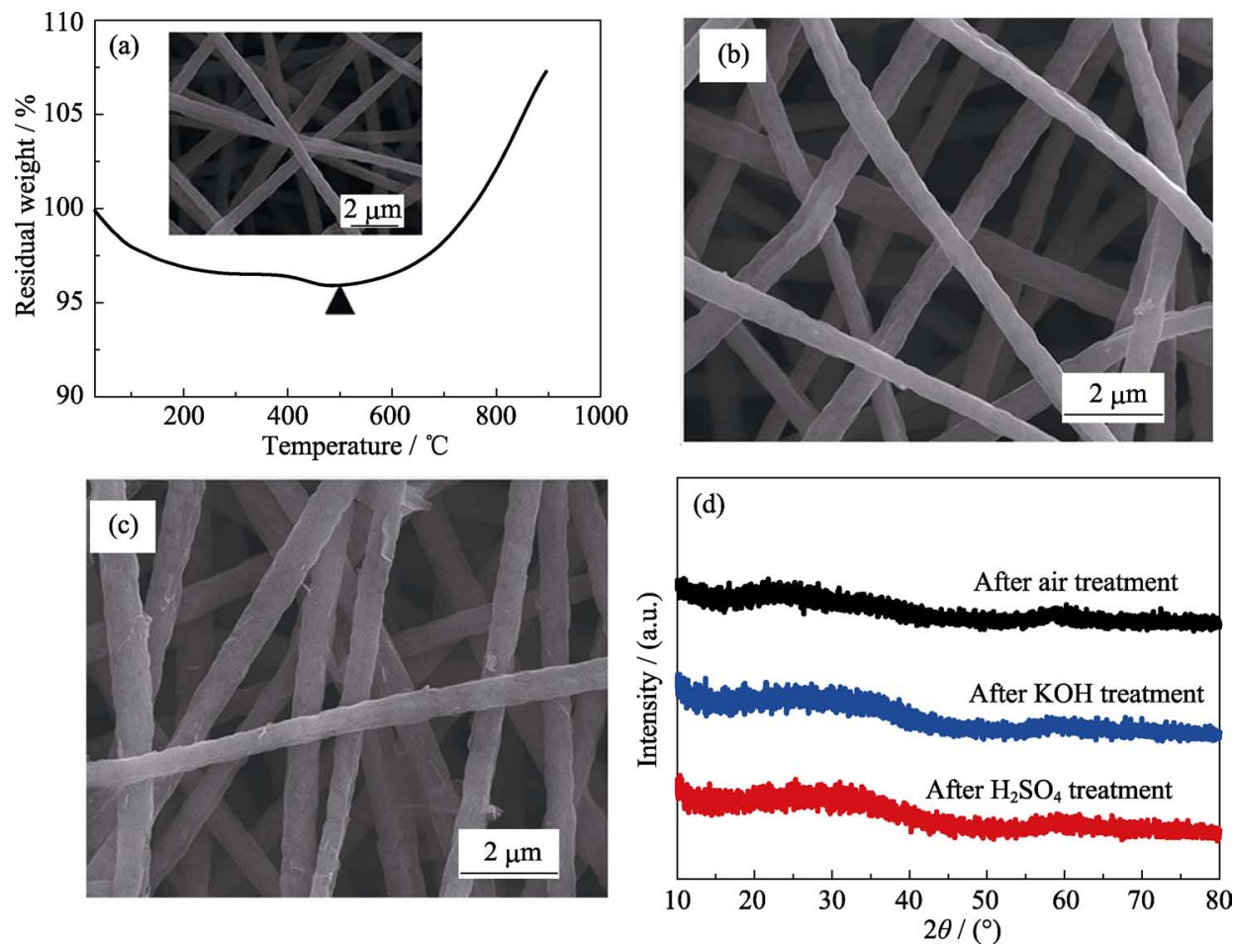

Fig. 5 Stability test results

(a) TGA curve of SiOC-15 in air, with inset showing SEM image after heating at $500^{\circ} \mathrm{C}$ in air for $1 \mathrm{~h}$; (b) SEM image of SiOC-15 after immersing in $1 \mathrm{~mol} / \mathrm{L} \mathrm{H}_{2} \mathrm{SO}_{4}$ solution at $90^{\circ} \mathrm{C}$ for $36 \mathrm{~h}$; (c) SEM image of SiOC- 15 after immersing in $6 \mathrm{~mol} / \mathrm{L} \mathrm{KOH}$ at $90^{\circ} \mathrm{C}$ for $36 \mathrm{~h}$; (d) XRD patterns of SiOC-15 after different treatments

\section{References:}

[1] YUAN Q, SONG Y. Research and development of continous SiC fiber and $\mathrm{SiC}_{\mathrm{f}} / \mathrm{SiC}$ composites. Journal of Inorganic Materials, 2016, 31(11): 1157-1165.

[2] HOJAMBERDIEV M, PRASAD R M, MORITA K, et al. Polymer-derived mesoporous SiOC/ZnO nanocomposite for the purification of water contaminated with organic dyes. Microporous and Mesoporous Materials, 2012, 151: 330-338.

[3] VANHAECKE E, IVANOVA S, DENEUVE A, et al. 1D SiC decoration of SiC macroscopic shapes for filtration devices. Journal of Materials Chemistry, 2008, 18: 4654-4662.

[4] KIM T E, JUON S M, PARK J H, et al. Silicon carbide fiber-reinforced composite membrane for high-temperature and low-humidity polymer exchange membrane fuel cells. International Journal of Hydrogen Energy, 2014, 39(29): 16474-16485.

[5] WU N, WANG Y, LEI Y, et al. Electrospun interconnected Fe-N/C nanofiber networks as efficient electrocatalysts for oxygen reduction reaction in acidic media. Scientific Reports, 2015, 5: 17396.

[6] WANG B, WANG Y, LEI Y, et al. Hierarchically porous SiC ultrathin fibers mat with enhanced mass transport, amphipathic property and high-temperature erosion resistance. Journal of Materials Chemistry A, 2014, 2(48): 20873-20881.

[7] WANG Y, HAN C, ZHENG D, et al. Large-scale, flexible and high-temperature resistant $\mathrm{ZrO}_{2} / \mathrm{SiC}$ ultrafine fibers with a radial gradient composition. Journal of Materials Chemistry A, 2014, 2(25): 9607-9612.

[8] COLOMBO P, MERA G, RIEDEL R, et al. Polymer-derived ceramics: 40 years of research and innovation in advanced ceramics. Journal of the American Ceramic Society, 2010, 93: 1805-1837.

[9] CHENG X, XIE Z, SONG Y, et al. Structure and properties of polycarbosilane synthesized from polydimethylsilane under high pressure. Journal of Applied Polymer Science, 2006, 99(3): 1188-1194.

[10] LIU H, BALKUS K J. Electrospinning of beta silicon carbide nanofibers. Materials Letters, 2009, 63(27): 2361-2364.

[11] EICK B M, YOUNGBLOOD J P. SiC nanofibers by pyrolysis of electrospun preceramic polymers. Journal of Materials Science, 2009, 44(1): 160-165.

[12] AYUTSEDE J, GANDHI M, SUKIGARA S, et al. Regeneration of bombyx mori silk by electrospinning. part 3: characterization of electrospun nonwoven mat. Polymer, 2005, 46(5): 1625-1634.

[13] HU J, PRABHAKARAN M P, DING X. Emulsion electrospinning of polycaprolactone: influence of surfactant type towards the scaffold properties. Journal of Biomaterials Science, Polymer, 2015, 26(1): 57-75.

[14] LI Y, KO F K, HAMAD W Y. Effects of emulsion droplet size on the structure of electrospun ultrafine biocomposite fibers with cellulose nanocrystals. Biomacromolecules, 2013, 14: 3801-3807.

[15] KOOBHONGSE S, LIU W, RENEKER D. Flat polymer ribbons and other shapes by electrospinning. Journal of Polymer Science Part B: Polymer Physics, 2001, 39(1): 2363-2377.

[16] JIANG H, FANG D, HSIAO B S, et al. Optimization and characterization of dextran membranes prepared by electrospinning. Biomacromolecules, 2004, 5(2): 326-333.

[17] KLEEBE H J, BLUM Y D. SiOC ceramic with high excess free carbon. Journal of the European Ceramic Society, 2008, 28(5): 1037-1042.

[18] KIM M, KIM J. Redox deposition of birnessite-type manganese oxide on silicon carbide microspheres for use as supercapacitor electrodes. ACS Applied Materials and Interfaces, 2014, 6(12): 9036-9045.

[19] WAN L Y, WANG H, GAO W, et al. An analysis of the tensile properties of nanofiber mats. Polymer, 2015, 73: 62-67. 


\section{静电纺聚碳硅烷制备 SiOC 超细纤维}

\section{吴 楠 ${ }^{1,2}$, WAN Lynn Yuqin ${ }^{2}$, 王应德 ${ }^{1}$, FRANK $\mathrm{KO}^{2}$}

(1. 国防科技大学 新型陶瓷纤维及其复合材料重点实验室, 长沙 410073; 2. 不列颠哥伦比亚大学 材料工程系, 温哥华 V6T 1Z4)

摘 要: 以聚碳硅烷(PCS)为先驱体, 采用静电纺丝法和先驱体转化法制备 SiOC 超细纤维, 研究 PCS 溶液浓度和表 面活性剂对纤维形貌和直径的影响。实验结果表明: 添加表面活性剂后, 纤维分布均匀, 串珠现象消失; 通过调节 溶液中 PCS 比例, 纤维直径分布范围为 500 900 nm。力学性能测试表明 SiOC 纤维毡的抗拉强度可达 $8.88 \mathrm{MPa}$ 。 SiOC 超细纤维毡也展现出优异的热稳定性和抗化学腐蚀性能, 在苛刻环境中可以作为催化剂载体和过滤材料使用。

关 键 词: 静电纺丝; 聚碳硅烷; 硅氧碳; 陶瓷纤维 中图分类号: TQ174 文献标识码: A 